
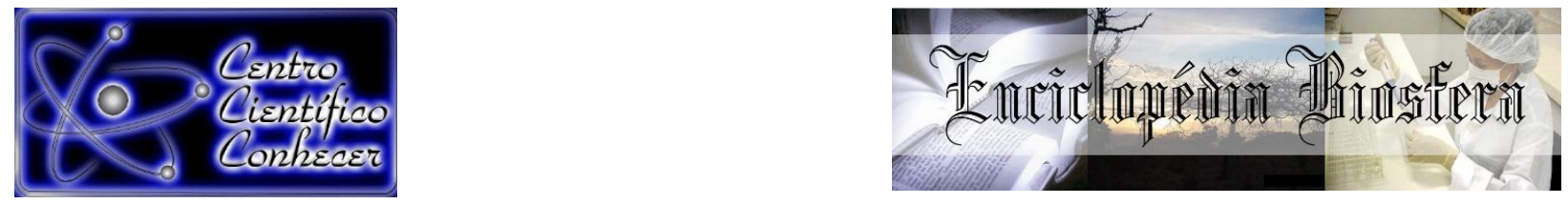

\title{
DIAGNÓSTICO DA ARBORIZAÇÃO URBANA DA AVENIDA PRESIDENTE VARGAS, SANTARÉM-PARÁ
}

\author{
Wendell da Silva Gil ${ }^{1}$, Lucas Cunha Ximenes ${ }^{2}$
}

${ }^{1}$ Bacharel em Engenharia Florestal, Universidade Federal do Oeste do Pará/Instituto de Biodiversidade e Florestas, Santarém-PA, Brasil. wendelldasilvagil@gmail.com

${ }^{2}$ Professor Mestre do curso de Engenharia Florestal da Universidade Federal do

Oeste do Pará/Instituto de Biodiversidade e Florestas, Santarém-PA, Brasil.

Recebido em: 06/04/2019 - Aprovado em: 10/06/2019 - Publicado em: 30/06/2019

DOI: 10.18677/EnciBio_2019A53

\begin{abstract}
RESUMO
O crescimento desordenado das cidades gera impactos negativos no que diz respeito às mudanças estruturais das paisagens naturais. No caso de ambientes urbanos, é necessário o planejamento adequado da arborização das cidades, visto ser importante instrumento para melhorar a qualidade de vida da população. Desta forma, o trabalho teve por objetivo realizar um levantamento qualitativo dos indivíduos arbóreos de um trecho da Avenida Presidente Vargas na cidade de Santarém - Pará, bem como avaliar a adequabilidade e subsidiar possíveis práticas silviculturais. A metodologia da pesquisa se deu através de inventário qualiquantitativo total das árvores com altura superior ou igual a dois metros, sendo avaliados 341 indivíduos. Os parâmetros qualitativos foram coletados de forma visual utilizando uma ficha de campo, em que se avaliaram as condições fitossanitárias, interferências na via, danos às calçadas e passeios, contato com a fiação e a necessidade de manejo. As espécies de maior frequência foram Mangifera indica L. (mangueira), com 35,8\%, e o Handroanthus riodocensis (ipê amarelo), com 26,3\%. A maior parte dos indivíduos pesquisados não se apresentou de forma inadequada na via, com exceção de alguns casos específicos onde se sugere práticas de manejo.
\end{abstract}

PALAVRAS-CHAVE: Adequabilidade, planejamento, Silvicultura urbana

\section{DIAGNOSIS OF THE URBAN AFFORESTATION OF AVENIDA PRESIDENTE VARGAS, SANTARÉM-PARÁ}

\begin{abstract}
The disorderly growth of cities generates negative impacts on structural changes in natural landscapes. In the case of urban environments, adequate planning of the afforestation of cities is necessary, since it is an important tool to improve the quality of life of the population. In this way, the objective of this work was to conduct a qualitative survey of tree individuals from a section of Presidente Vargas Avenue in
\end{abstract}


the city of Santarém - Pará, as well as to evaluate the suitability and subsidize possible silvicultural practices. The research methodology was based on a total qualitative and quantitative inventory of trees with a height greater than or equal to two meters, and 341 individuals were evaluated. The qualitative parameters were collected visually using a field file, in which the phytosanitary conditions, interference in the road, damages to sidewalks and sidewalks, contact with the wiring and the need for handling were evaluated. The most frequent species were Mangifera indica L. (hose), with $35.8 \%$, and Handroanthus riodocensis (yellow ipê), with $26.3 \%$. Most of the individuals surveyed did not present themselves in an inadequate way, with the exception of some specific cases where management practices are suggested.

KEYWORDS: Planning, suitability, urban forestry

\section{INTRODUÇÃO}

A cidade é uma das grandes invenções do homem, onde se encontram vários produtos e serviços essenciais à vida humana (MOURA, 2010). Em vários países, grande parte da população vive nas cidades (MILANO; DALCIN, 2000), sendo que no Brasil a maioria (84,35\%) vive em áreas urbanas (IBGE, 2010). É sabido que o crescimento das cidades de forma acelerada e desordenada traz consigo impactos ambientais negativos, pois substitui ecossistemas que anteriormente eram "verdes" por pavimentações e edificações. Com tudo isso, a qualidade de vida da população é diretamente afetada (RESENDE, 2011).

Neste aspecto, o planejamento adequado da arborização urbana vem a ser importante, pois se trata de uma ferramenta de melhoria da qualidade de vida das populações urbanas, representada principalmente pelo componente arbóreo (MILLANO; DALCIN, 2000). Locais com presença de árvores são indiscutivelmente mais agradáveis aos sentidos do ser humano, pois melhoram o microclima, interferem na direção e velocidade dos ventos, proporcionam zonas de sombreamento e influenciam visualmente os núcleos urbanos, trazendo mais beleza às paisagens (SANCHOTENE, 1994). Além disso, estes espaços minimizam os efeitos da poluição sonora, diminuem o impacto da água da chuva, bem como o escoamento superficial, aumentam a qualidade do ar e atuam no papel de preservação da fauna silvestre (PIVETTA; SILVA FILHO, 2002).

Estudos relacionados à arborização urbana se fazem cada vez mais necessários na medida em que eles comprovam a importância para a qualidade de vida nas cidades (PAIVA; GONÇALVES, 2002). Conhecer as características do meio urbano pode garantir o sucesso da arborização, bem como também a relevância de se conhecer a vegetação adequada para a arborização urbana (DANTAS; SOUSA, 2004).

Os trabalhos desenvolvidos nesta área servem de parâmetro instrutivo (BARROS et al., 2010), resultando em ações direcionadas ao planejamento de atividades acerca do manejo, que junto com o aporte da sociedade são fundamentais para o sucesso da arborização (SILVA FILHO et al., 2002).

As vantagens da arborização das ruas de uma cidade estão diretamente ligadas à qualidade do planejamento (SCARAMUSSA, 2013). Muitas cidades brasileiras não apresentam planejamento adequado de arborização urbana (ALMEIDA, 2009), já que muitos dos projetos são baseados em saberes empíricos e carentes de conhecimento técnico do assunto (BORTOLETO et al., 2006) e ruas 
arborizadas sem nenhum planejamento prévio são passiveis de prejuízos ao poder público e à população de forma geral (SCHUCH, 2006).

São muitos os danos causados por essa falta de planejamento, dentre os mais importantes, destacam-se: danos às calçadas e às edificações, devido ao crescimento das raízes; interferência nas redes de eletricidade e comunicação devido ao contato com as copas das árvores; danificação no encanamento subterrâneo pelas raízes; entupimento do sistema de esgoto causado pela queda das folhas e frutos; além da interferência no livre trânsito de pessoas e veículos ocasionado pela queda de galhos, frutos e até mesmo da árvore em si (CHRISTO; DIAS, 2006).

Um bom planejamento baseia-se no conhecimento das características qualiquantitativas das árvores urbanas (PAIVA, 2009), associado ao acompanhamento das árvores já implantadas, que permite a avaliação e subsidia práticas de manejo adequadas de acordo com a espécie, a localização na via (MINHOTO et al., 2009) e as condições fitossanitárias (SCHUCH, 2006).

Desta forma, o objetivo deste estudo foi realizar um levantamento qualitativo da arborização urbana de um trecho da Avenida Presidente Vargas em SantarémPA, a fim de avaliar a adequabilidade das espécies presentes na área de estudo e subsidiar práticas de manejo adequadas para a arborização da via.

Área de estudo

\section{MATERIAL E MÉTODOS}

O estudo foi realizado na Avenida Presidente Vargas, localizada no município de Santarém, região oeste do estado do Pará $\left(2^{\circ} 26^{\prime} 18^{\prime \prime}\right.$ de latitude Sul e $54^{\circ} 42^{\prime} 00^{\prime \prime}$ de longitude Oeste) (Figura 1). A cidade possui cerca de 294.580 habitantes e uma área de 17.898.389 km² (IBGE, 2010). O clima da região de acordo com INMET (2017) é do tipo quente e úmido, com índice de precipitação e temperatura média anual de $1920 \mathrm{~mm}$ e 25 a $28^{\circ} \mathrm{C}$, respectivamente.

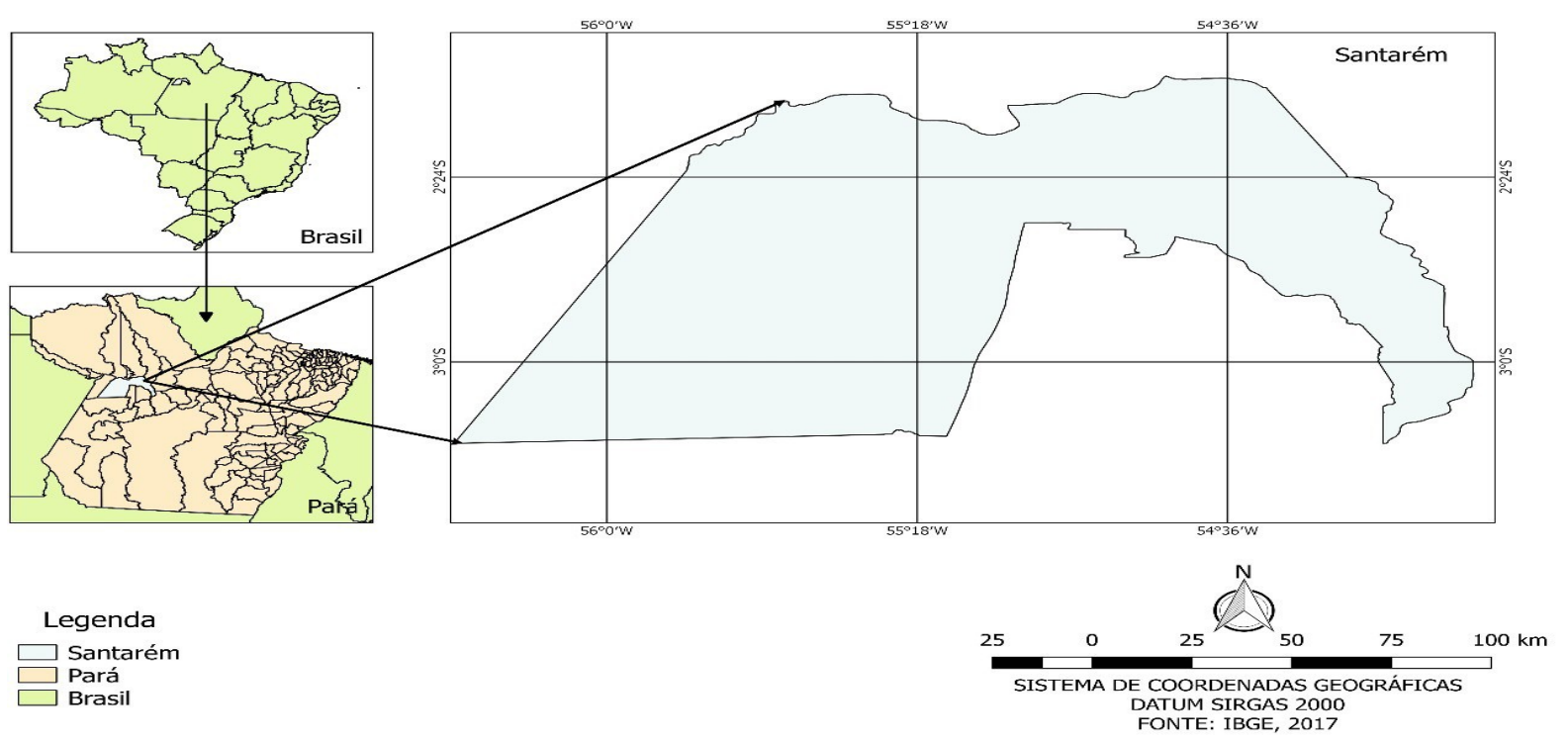

FIGURA 1 - Localização do município de Santarém - PA.

O trecho da Avenida Presidente Vargas analisado compreendeu desde a Avenida Santarém - Cuiabá (BR - 163) até a Avenida Curuá - Una (PA - 370) 
(Figura 2), perfazendo uma distância de $2,95 \mathrm{~km}$, da via que no total possui $4,79 \mathrm{~km}$. A avenida em questão é pavimentada e possui canteiro central, com presença de edificações tanto domiciliares quanto comerciais, redes elétricas e de comunicação, sistema de distribuição de água encanada e esgoto, além do significativo fluxo de automóveis e pessoas. A escolha da área de estudo se deu por se tratar de uma importante via da cidade, a mesma é bastante arborizada.

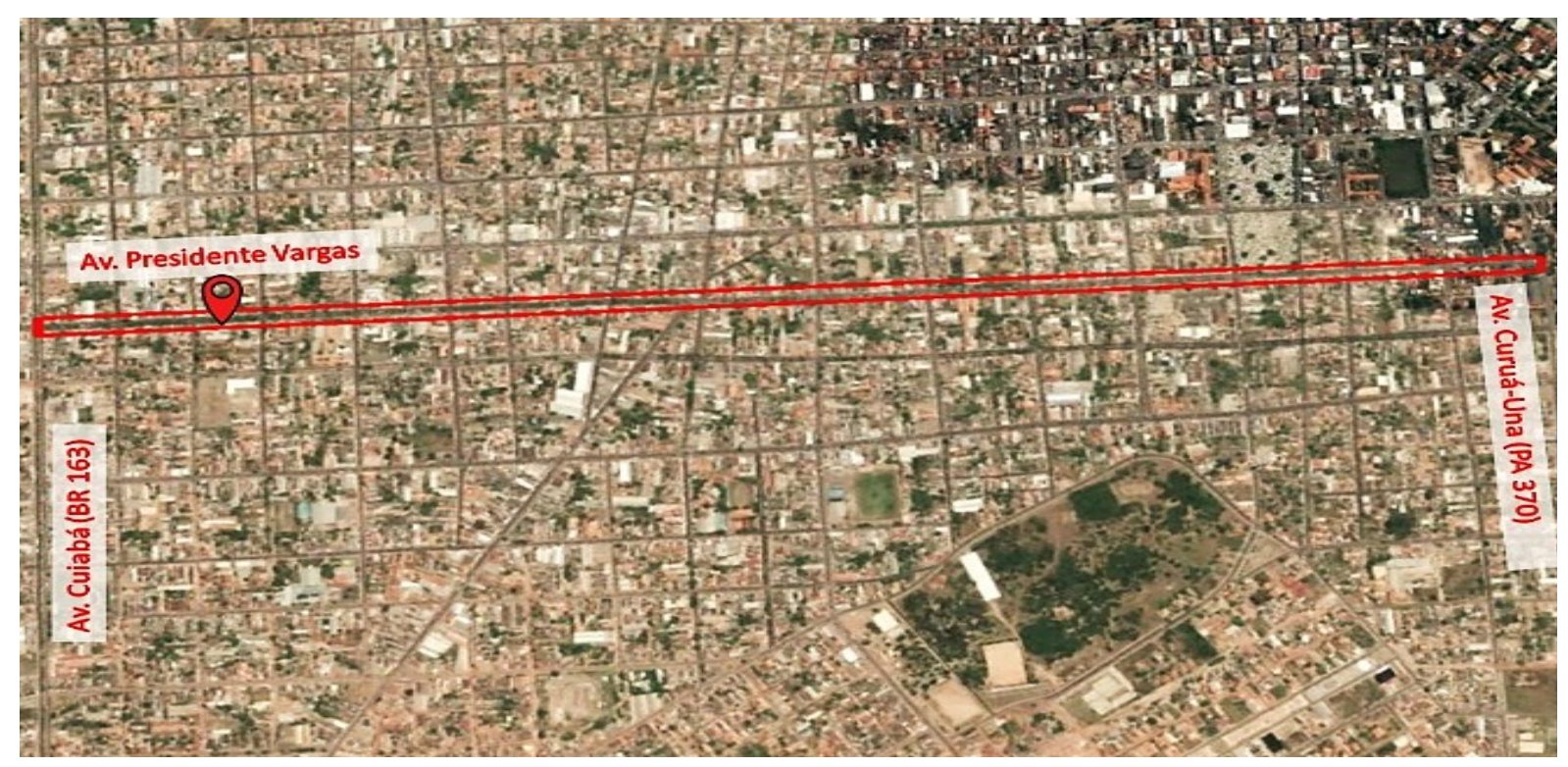

FIGURA 2 - Trecho inventariado para levantamento da arborização urbana na Avenida Presidente Vargas, Santarém - Pará. FONTE: Adaptado de Google Earth (2019).

\section{Coleta de dados}

A coleta de dados foi realizada nos meses de maio e junho de 2018 por meio de inventário do tipo censo qualitativo dos indivíduos arbóreos presentes em um trecho da avenida, no qual o nível de inclusão determinado foi altura total estimada visualmente igual ou superior a dois metros. Os parâmetros qualitativos empregados no trabalho tiveram como base estudos realizados por Nunes et al. (2013), que resultou na elaboração de uma ficha de campo com as seguintes variáveis:

- Espécie: Identificação das espécies, com auxílio de um identificador botânico e de literatura especifica feita através do nome vulgar para posterior verificação do nome cientifico e família botânica. Ainda com auxílio de bibliografia especializada (HARRI et al., 2003; LORENZI, 2008), foi possível classificar as espécies quanto a origem (nativas e exóticas).

- Posição da copa: Trata-se da posição da copa das árvores em detrimento ao espaço urbano e suas estruturas. Consideraram-se três situações: Sem interferência, quando a copa não interfere nas estruturas da via; Rua, quando a copa está atingindo a rua; e Residência, quando o crescimento da copa atinge as residências.

- Sanidade da copa: Trata-se da sanidade da copa das árvores avaliada de forma visual pela aparência física. Foram considerados quatro aspectos: 
Sadias, quando as copas das árvores não apresentavam problemas fitossanitários; Cupim, quando a copa apresentava ataque de cupins; Parasitas, quando esta apresentava a presença de parasitas (ervas de passarinho); e Podridão, quando os galhos da copa demonstravam sinais de apodrecimento.

- Posição do indivíduo: Referente à posição em que os indivíduos se encontravam na via. Foram verificadas duas situações: Canteiro central e Calçada.

- Posição do fuste: Refere-se à posição do crescimento do fuste dos indivíduos arbóreos, o qual foi classificado em três aspectos: Fuste normal, quando o fuste apresentava crescimento retilíneo; Rua, quando o fuste demonstrava tendência de crescimento no sentido da rua; e Residência, quando o mesmo apresentava crescimento direcionado às casas.

- Sanidade do fuste: Diz respeito à sanidade do fuste das árvores, e foram estabelecidas três classificações a serem avaliadas de forma visual: Sadios, quando os fustes não apresentavam problemas quanto a sua sanidade; Cupim, quando o fuste se mostrava infestado por cupim; e Podridão, quando apresentava sinais de apodrecimento.

- Posição da raiz: Trata-se da posição das raízes na via. Determinaram-se quatro situações: Sem afloramento, quando a raiz se encontrava sem afloramento, não interferindo na estrutura de calçadas e canteiro central; Sem afloramento com rachadura, quando não havia afloramento, porém apresentava rachaduras nas calçadas e canteiro central; Afloramento contido, quando ocorre o afloramento das raízes sem causar danos estruturais; e Afloramento com rachadura, quando estas se apresentavam afloradas e causando rachaduras nas calçadas.

- Sanidade da raiz: Refere-se às condições fitossanitárias das raízes. Estabelecida visualmente por quatro aspectos: Sem danos, quando as raízes se encontravam sem danos visíveis; Raiz cortada, quando estas se apresentavam com algum trauma antrópico; Apodrecimento, quando as raízes exibiam sinais de podridão; e Raiz estrangulada, quando estas mostravam sinais de estrangulamento, ocasionada pelas estruturas presentes na via.

- Fiação: Trata-se da verificação de situações de conflito entre a fiação elétrica e/ou de comunicação e as árvores. Três situações foram determinadas: Ausente, quando não há conflito entre a fiação e os indivíduos arbóreos; Potencial, quando as árvores e a fiação estão em potencial risco de conflito; e Presente, quando ocorre o conflito da copa das árvores com a fiação.

- Manejo: Refere-se às necessidades de manejo dos indivíduos arbóreos presentes na via. Foram determinados quatro tipos de parâmetros: Ausente, quando não há necessidade de manejo; Poda, quando se detectou a necessidade de poda da árvore; Substituição, quando o indivíduo arbóreo apresentou necessidade de ser substituído, visto que a estrutura permite a implantação de outra árvore no local; e Remoção, quando houve a necessidade de remover a árvore da via, devido à falta de condições estruturais para se ter uma árvore no determinado local.

Análise dos dados

Os dados foram processados utilizando planilhas eletrônicas. Foram plotados gráficos com as porcentagens acerca de cada parâmetro avaliado em campo. 


\section{- Levantamento arbóreo}

\section{RESULTADOS E DISCUSSÃO}

Foram inventariados 341 indivíduos arbóreos no trecho da avenida estudada, sendo estes identificados e classificados em 21 espécies e 12 famílias (quadro 1). Deste total, $59 \%$ são de origem exótica e $41 \%$ de origem nativa. No levantamento realizado por Santos (2018) no município de Cuité na Paraíba, verificou-se que a maioria das espécies é de origem exótica, semelhante ao que foi observado no trecho da via neste estudo.

Espécies exóticas quando invasoras consistem na segunda maior causa de queda da biodiversidade no mundo (GIPS, 2005). A inserção de espécies exóticas é de fácil observação nos centros urbanos (SANTOS et al., 2008). A alta frequência de indivíduos arbóreos exóticos nas cidades exerce importante papel de propagador de invasões biológicas (DEHNEN-SCHMUTZ et al., 2007), podendo causar impactos negativos no âmbito econômico, social (ZILLER et al., 2007) e ambiental (ZILLER, 2000).

A troca gradativa das espécies exóticas por nativas é apontada como solução para garantir a conservação biológica dos ecossistemas naturais brasileiros que se encontram próximos às zonas urbanas, beneficiando o meio ambiente e a população (ZILLER et al., 2007; PAULA et al., 2013).

Em estudo também realizado na cidade de Santarém (PA), Dantas et al. (2018), avaliando o comportamento de Azadiractha indica (nim indiano), na arborização desta cidade, mesmo tendo a espécie apresentado aparente potencial no seu estabelecimento, os autores recomendam que outras pesquisas sejam desenvolvidas com o objetivo de estudar o uso e o desenvolvimento de espécies nativas na arborização urbana, para que se possa fomentar a adoção de espécies nativas na arborização urbana.

As cinco espécies de maior frequência foram Mangifera indica L. (mangueira) com 122 indivíduos, correspondendo a $35,8 \%$ do total, Handroanthus riodocensis (ipê amarelo) com 76 exemplares - 22,3\% do total, Licania tomentosa (oiti) com 35 indivíduos e $10,3 \%$ do total, Pithecellobium Dulce (mata-fome espinhenta) com 26 exemplares $-7,9 \%$ de ocorrência e a Diplotropis purpurea (sapupira) com 23 indivíduos, $6,7 \%$ do total.

Em somatório, as cinco espécies compreenderam o total de $83 \%$ do total de espécies inventariadas. A alta frequência de $M$. indica L. (mangueira) é similar a estudos realizados por Gomes et al. (2016) em uma praça de Macapá - AP, no qual cerca de $35,7 \%$ dos indivíduos inventariados correspondiam à espécie, assim como a quantidade de indivíduos de $L$. tomentosa (oiti) apresentada em estudo realizado em Campina Grande - PB (ARAÚJJO et al., 2009).

Sabe-se que as primeiras sementes da espécie $M$. indica $\mathrm{L}$. chegaram a solos amazônicos entre os séculos XVIII e XIX, se adaptaram muito bem ao clima (AIROZA, 2008), sendo a cidade de Belém - PA pioneira na implantação de árvores, ocorrendo assim a plantação massiva de mangueiras (LOUREIRO; BARBOSA, 2010), hoje conhecida como Cidade das Mangueiras.

QUADRO 1 - Lista de espécies inventariadas na Avenida Presidente Vargas, Santarém, PA.

\begin{tabular}{lccc} 
Família/Nome científico & Nome comum & No & Origem \\
\hline Anarcadiaceae & Mangueira & 122 & Exótica \\
Mangifera indica L. & ENCICLOPÉDIA BIOSFERA, Centro Científico Conhecer - Goiânia, v.16 n.29; p. 6 & 2019
\end{tabular}




\begin{tabular}{|c|c|c|c|}
\hline \multicolumn{4}{|l|}{ Arecaceae } \\
\hline Pritchardia pacifica & Palmeira leque de Fiji & 1 & Exótica \\
\hline Roystonea oleracea & Palmeira imperial & 2 & Exótica \\
\hline Roystonea regia & Palmeira real & 3 & Exótica \\
\hline Bignoniaceae & & & \\
\hline Crescentia cujete L. & Cuieira & 1 & Exótica \\
\hline Grazielodendron riodocensis & Ipê rosa & 1 & Nativa \\
\hline $\begin{array}{l}\text { Handroanthus riodocensis } \\
\text { Chrysobalanaceae }\end{array}$ & Ipê amarelo & 76 & Nativa \\
\hline Licania tomentosa & Oiti & 35 & Nativa \\
\hline Combretaceae & & & \\
\hline $\begin{array}{l}\text { Terminalia catappa L. } \\
\text { Fabaceae }\end{array}$ & Castanhola & 5 & Exótica \\
\hline Pithecellobium dulce & Mata-fome espinhenta & 26 & Exótica \\
\hline $\begin{array}{l}\text { Leguminoseae } \\
\text { Cassia fistula }\end{array}$ & Chuva-de-ouro & 1 & Fxótica \\
\hline Diplotropis purpúrea & Sapupira & 23 & Nativa \\
\hline Senna silllnea & Acácia de Sião & 3 & Exótica \\
\hline $\begin{array}{l}\text { Tamarindus indica L. } \\
\text { Malpighiaceae }\end{array}$ & Tamarindo & 3 & Exótica \\
\hline Byrsonima crassifólia & Murici & 1 & Nativa \\
\hline $\begin{array}{l}\text { Lophanthera lactescens } \\
\text { Meliaceae }\end{array}$ & Lanterneira & 2 & Nativa \\
\hline $\begin{array}{l}\text { Azadirachta indica } \\
\text { Moraceae }\end{array}$ & Nim & 7 & Exótica \\
\hline $\begin{array}{l}\text { Ficus benjamina L. } \\
\text { Myrtaceae }\end{array}$ & Fícus & 11 & Exótica \\
\hline Psidium guajava L. & Goiabeira & 3 & Nativa \\
\hline $\begin{array}{l}\text { Syzygium malaccense L. } \\
\text { Rutaceae }\end{array}$ & Jambeiro & 14 & Exótica \\
\hline Citrus limon & Limoeiro & 1 & Exótica \\
\hline
\end{tabular}

Na Avenida Presidente Vargas em Santarém - PA, os exemplares de $M$. indica L. (mangueira) foram plantados por alunos da Universidade Federal do Pará (hoje Universidade Federal do Oeste do Pará), em um trote ecológico realizado na década de 1980 (BRITO; SOUZA, 2017).

\section{- Posição da copa}

No que tange à posição da copa, a população se apresentou com $54 \%$ dos indivíduos com posição classificada como sem interferência, quando não está projetada para rua ou residências. Tal fato pode ser justificado, pois a maior parte dos indivíduos está disposta no canteiro central da avenida (67\%). No entanto, é preciso atentar-se para os $46 \%$ dos indivíduos que possuem as copas projetadas para rua e residências, e que segundo Silva et al. (2012) podem acarretar em problemas ao trânsito de veículos e pessoas, bem como danos às edificações. A espécie Pithecellobium dulce (mata-fome espinhenta) contribui para este percentual elevado, já que a espécie apresentou $54 \%$ dos indivíduos arbóreos com a copa projetada para as residências e $23 \%$ para a rua. 
Como solução para os problemas indicados, recomenda-se a realização da poda de conformação, que de acordo com Oliveira (2013), consiste na remoção de galhos que estejam interferindo em edificações, iluminação viária, rede elétrica e de comunicação, sinalização de trânsito, considerando a harmonia e beleza da árvore. Quanto à época para realizar o procedimento, aconselha-se o verão, a fim de evitar chuvas que venham a prejudicar as práticas de podas e atentando-se para a fenologia da espécie (PORTO et al., 2013).

\section{- Ataque de pragas na copa}

A respeito da fitossanidade da copa, de maneira geral observaram-se boas condições, pois $79 \%$ das árvores não apresentaram problemas de ataque por cupins ou parasita, $15 \%$ estavam atacadas por parasitas (erva de passarinho) e 6\% por cupim. Para resolver os casos de ataques de cupins e parasitas, indica-se a poda de limpeza, que visa à retirada apenas dos galhos podres, quebrados ou atacados por pragas (OLIVEIRA, 2013; PORTO et al., 2013).

\section{- Fitossanidade do fuste e raiz}

No que diz respeito à fitossanidade do fuste, $91 \%$ dos indivíduos inventariados não apresentaram podridão ou ataque de cupins, $5 \%$ sofreram ataque de cupins e $4 \%$ podridão. Apesar de apresentar baixo percentual de ataque por pragas e parasitas, a situação encontrada na via não está em conformidade com o que é sugerido para arborização urbana, em que o recomendado é que uma espécie não ultrapasse $10 \%$ do total de indivíduos de uma população (PIVETTA; SILVA FILHO, 2002). Segundo Milano e Dalcin (2000), quando há baixa diversidade de espécies ocorre o aumento do risco de perda da arborização pelo ataque de pragas e doenças.

Quanto às raízes, 99\% dos indivíduos encontravam-se sem problemas acerca da fitossanidade. O percentual de árvores em boas condições fitossanitárias apresentados corroboram com estudo de Barros et al. (2010), em que apenas 1,1\% dos indivíduos apresentaram algum tipo de problema fitossanitário.

\section{- Posição da raiz}

Com relação à disposição radicular dos indivíduos, grande parte da população (61\%) não apresentou afloramento de raízes, com exceção de indivíduos como os da espécie $F$. benjamina L. (fícus) que apresentaram $46 \%$ dos indivíduos sem afloramento, porém causando rachaduras nos passeios e $36 \%$ com afloramento e rachaduras. Em estudo realizado por Gramignolli et al. (2016), a espécie $F$. benjamina L. (fícus) também está associada a rachaduras de calçadas e vias em virtude de suas raízes superficiais.

Ainda que $F$. benjamina $L$. venha sendo empregada muito popularmente na arborização urbana, suas raízes, por apresentar crescimento superficial, causam problemas às construções e sistemas de distribuição de água e esgoto (PINTO; CORREAA, 2010; CARVALHO FILHO et. al, 2013). Devido ao sistema radicular agressivo, a espécie não é recomendada para compor a arborização de vias públicas (SMAAP, 2016). Com isso, recomenda-se evitar o plantio e realizar a substituição (CARVALHO et al., 2013), por espécies com sistema radicular pivotante ou axial profundo (PORTO et al., 2013).

Outra espécie que apresentou problema em relação ao sistema radicular foi $S$. malaccense $\mathrm{L}$ (jambeiro), frutífera de origem exótica que tem como característica 
fuste retilíneo, copa de formato cônico, com altura de sete a 12 metros em média (HARRI et al., 2003), foi apontado $36 \%$ dos indivíduos causando rachaduras às calçadas e da via mesmo sem afloramento de raízes e $36 \%$ com afloramento e rachaduras.

\section{- Conflito com a fiação}

Com relação ao conflito dos indivíduos arbóreos com as redes elétricas e de comunicação, $60 \%$ da população geral inventariada apresentou ausência de conflito, resultado muito próximo ao encontrado por Silva et al. (2012) na cidade de Jerônimo Monteiro, Espírito Santo. Entretanto, ainda existe um alto número de indivíduos que apresentam conflitos com a fiação, como é o caso da espécie $F$. benjamina L. (fícus), que apresentou $64 \%$ dos indivíduos mantendo contato direto com as redes e $9 \%$ com contato em potencial.

Por apresentar elevado vigor de crescimento aéreo com altura média de 20 30 metros (UFRJ, 2018), a espécie não é recomendada para a arborização de vias públicas (HARRI et. al, 2003), sendo que em algumas cidades a utilização é proibida por causa de suas características destrutivas ao ambiente urbano (CARVALHO FILHO et. al, 2013). Indica-se a substituição dos indivíduos encontrados na via, optando por espécies nativas, visando o bem-estar da população (CARVALHO et al., 2013), como por exemplo a Schinus terebinthifolius Raddi (aroeira), que apresenta copa globosa, mas de pequeno porte (PORTO et al., 2013).

A espécie $S$. malaccense L. (jambeiro) também apresentou problemas com a fiação, com $57 \%$ dos indivíduos conflitando com as redes e $36 \%$ com potencial conflito. O caso desta espécie torna-se difícil de resolver na via, visto que a poda não é recomendada, uma vez que a árvore perderia a característica ornamental (HARRI et al., 2003). Neste caso, recomenda-se a substituição dos indivíduos por árvores indicadas para arborização que apresentem porte adequado (BARCELLOS et al., 2012), por exemplo, Senna macranthera (manduirana) (RUBIO et. Al., 2018).

A espécie Licania tomentosa (oiti) teve $46 \%$ dos indivíduos em conflito com a fiação e $23 \%$ em potencial conflito. Isso pode ser justificado por se tratar de uma espécie de copa densa e arredondada que pode chegar a uma altura de 20 metros e que por isso é mais indicada para a arborização de parques e praças. Para a implantação em ruas e avenidas, faz-se necessário a adoção do critério de que sejam plantadas em canteiros centrais com largura mínima de três metros (SEMAS, 2017), o que vai de encontro com árvores presentes na avenida estudada em Santarém, pois $94 \%$ dos indivíduos arbóreos levantados neste estudo se encontram nas calçadas.

\section{- Necessidade de manejo}

No quesito manejo, mais especificamente quanto à necessidade de poda, observou-se proximidade entre a necessidade ou não do trato silvicultural, em que $51 \%$ dos indivíduos não apresentam atualmente necessidade de poda. Caso semelhante foi constatado por Schallenberger et al. (2013) na cidade de Mangueirinha (PR), onde $51,8 \%$ das árvores não necessitavam de podas.

Os dados a cerca dos indivíduos que necessitam de poda podem ser justificados em razão das espécies de grande representatividade da população apresentarem necessidade de poda em sua maioria, entre estas estão: Syzygium malaccense L. (jambeiro) - 92\%, Pithecellobium dulce (mata-fome espinhenta) $84 \%$, Ficus benjamina L. (fícus) $-70 \%$ e Licania tomentosa (oiti) - $69 \%$, sendo que as porcentagens são para o total de indivíduos por espécie. Destas, as espécies $S$. 
malaccense L. (jambeiro), F. benjamina L. (fícus) e a L. tomentosa (oiti), têm a necessidade de poda diretamente ligada com a questão de conflito da copa com a fiação, enquanto a $P$. dulce (mata-fome espinhenta) está relacionada com posição da copa dos indivíduos projetadas para a via e residências.

A poda se destaca como principal trato silvicultural para a conservação da arborização do meio urbano, tendo por objetivo garantir que as árvores desempenhem suas funções nas cidades em equilíbrio com as edificações, redes elétricas e de comunicação, bem como a segurança e bem-estar da população (OLIVEIRA, 2005), o que justifica a necessidade de poda das espécies citadas.

O elevado índice quanto à necessidade de poda apresentado pela espécie $S$. malaccense L. (jambeiro) pode ser justificado pelo fato de ser uma árvore de grande porte (sete a 12 metros) com a copa densa (HARRI et al., 2003). Os resultados corroboram com o estudo feito no município de Manaquiri (AM), em que a espécie apresentou elevado problema com a fiação (GUIMARÃES et al., 2014).

Os indivíduos de Pithecellobium dulce (mata-fome espinhenta) que apresentam necessidade de poda possuem relação direta com o fato de estarem projetados para a via e residências, e isto pode ser explicado porque trata-se de uma espécie que apresenta crescimento de tronco retorcido e irregular (LORENZI, 1998). Não é uma espécie recomendada para a arborização pelos espinhos presentes no fuste, crescimento das raízes e irregularidade do fuste (LIMA NETO; MELO E SOUZA, 2011), principalmente para vias. Em meio às condições apresentadas na via, aconselha-se a substituição gradual por espécies adequadas ao meio urbano (RUBIO et al., 2018), de preferência nativas (ZILLER et al., 2007).

O Ficus benjamina L. (fícus), por sua vez, é uma espécie de fácil adaptação climática e de solo, além de apresentar uma copa de rápido crescimento e muita densa (GOMES et al., 2017). Devido a estas características associadas à falta de conhecimento da população sobre as características físicas e biológicas, a espécie vem sendo introduzida na arborização de cidades, o que gera problemas com a fiação (CARVALHO et al., 2013). A prática de manejo mais utilizada para resolver o problema é a poda, muito embora a ação estimule novas brotações dos galhos que tão logo alcançarão novamente os fios (VELASCO, 2003). Portanto, para a via em questão, por se tratar de uma espécie não indicada, recomenda-se a substituição por indivíduos de espécies nativas adequadas.

A L. tomentosa (oiti) é uma espécie de grande porte (LORENZI, 2008), o que justifica o percentual de indivíduos que necessitam de poda. Vem sendo muito utilizada na arborização de cidades por causa de algumas características como fornecer boa sombra e resposta favorável às ações de poda (SILVA et al., 2012), com isso recomenda-se a poda para evitar o contato com a fiação (OLIVEIRA, 2013).

\section{- Espécies frutíferas presentes na via}

No que diz respeito às espécies frutíferas encontradas ao longo do trecho da via, é preferível a utilização das que produzem frutos pequenos, leves e não carnosos (BIONDI; ALTHAUS, 2005), já que segundo Cemig (2011), espécimes que produzem frutos carnosos podem causar danos a automóveis e lesões a pedestres. Entre as espécies frutíferas encontradas, e não recomendadas segundo a literatura estão: Mangifera indica L. (mangueira) e o Syzygium malaccense L. (jambeiro) devido aos frutos grandes, sendo que a mangueira trata-se da espécie de maior frequência no trecho da rua em estudo. 
A população arbórea da Avenida Presidente Vargas apresentou uma espécie frutífera recomendada para a arborização urbana de vias segundo SMVMAPSP (2015), que é a Licania tomentosa (oiti) que também está entre as mais frequentes com 35 indivíduos.

\section{CONCLUSÃO}

Ao avaliar a adequabilidade das árvores presentes na via, constatou-se que a avenida Presidente Vargas necessita de ações de manutenção e monitoramento da arborização existente, bem como o planejamento de implantação futura de algumas espécies, visto que a falta de organização neste sentido pode vir a causar maiores prejuízos para o poder público e para a população em geral. Portanto, recomenda-se a criação de um plano de arborização para o município a fim de potencializar os benefícios das árvores para o meio urbano.

\section{REFERÊNCIAS}

AIROZA, L. O. V. Cidade das Mangueiras: aclimatação das mangueiras e arborização dos logradouros belenenses (1616-1991). Dissertação (Mestrado em História Social da Amazônia) - Centro de Filosofia e Ciências Humanas, Universidade Federal do Pará, Belém - PA, 2008.

ALMEIDA, D. N. Análise da arborização urbana de cinco cidades da região norte do Estado do Mato Grosso. Cuiabá - MT, 2009.

ARAÚJO, A. C.; RIBEIRO, I. A. M.; MORAIS, M. S.; ARAÚJO, J. L. O. Análise qualiquantitativa da arborização no Bairro Presidente Médici, Campina Grande-PB. . Revista da Sociedade Brasileira de Arborização Urbana, Piracicaba - SP, 2009.

BARCELLOS, A.; WOJCIKIEWICZ, C. R.; LUBASZEWSKI, E. A.; MAZUCHOWSKI, J. Z.; CONCEIÇÃO, et al.,; Manual para elaboração do plano municipal de arborização urbana. Paraná, 2012.

BARROS, E. F. S.; GUILHERME, F. A. G.; CARVALHO, R. S. Arborização urbana em quadras de diferentes padrões construtivos na cidade de Jataí. Revista Árvore, Viçosa - MG, 2010.

BIONDI, D.; ALTHAUS, M. Árvores de rua de Curitiba: cultivo e manejo. Curitiba: FUPEF, 2005.

BORTOLETO, S.; SILVA FILHO, D. F.; LIMA, A. M L. P. Prioridades de Manejo para a Arborização Viária da Estância de Águas de São Pedro-SP. Revista da Sociedade Brasileira de Arborização Urbana, Piracicaba - SP, 2006.

BRITO, G.; SOUZA, J. Calouros da UFOPA plantam e distribuem mudas no Residencial Salvação. Disponível em: <https://g1.globo.com/pa/santaremregiao/noticia/calouros-da-ufopas-plantam-edistribuem-mudas-no-residencial-salvacao>. Acesso em: 13 de dezembro de 2018.

CARVALHO, A. A.; SILVA, L. F.; LIMA, A. P.; SANTOS, T. P. A inviabilidade do ficus (Ficus benjamina L.) para arborização urbana. XII JEPEX - Universidade Federal Rural de Pernambuco, Recife - PE, 2013. 
CARVALHO FILHO, G. C.; PENNA, L. F. R.; MENDONÇA, I. C. Arborização urbana das principais vias públicas da cidade de Jampruca - MG: Uma abordagem quantitativa. Governador Valadares - MG, 2013.

CEMIG - Companhia Energética de Minas Gerais. Manual de arborização urbana. 2011.

CHRISTO, J. A.; DIAS, A. N. Inventário Florestal da Arborização Urbana do Centro da Cidade de Prudentópolis - PR, Paraná, 2006.

DANTAS, I. C.; SOUZA, C. M. C. de. Arborização urbana na cidade de Campina Grande - PB: Inventário e suas espécies. Revista de Biologia e Ciências da Terra. 2004.

DANTAS, R. C. O.; BEZERRA, T. G.; VIEIRA, T. A. Arborização urbana com nim indiano na cidade de Santarém, Pará, Brasil. Revista da Sociedade Brasileira de Arborização Urbana, v. 13, n. 2, p.37-46, 2018.

DEHNEN-SCHMUTZ, K.; TOUZA, J.; PERRINGS, C.; WILLIAMSON, M. A century of the ornamental plant trade and its impact on invasion success. Diversity and Distribution, 2007.

GISP - Programa Global de Espécies Invasoras. 2005. América do Sul invadida. A crescente ameaça das espécies exóticas invasoras.

GOMES, E. M. C.; RODRIGUES, D. M. S.; SANTOS, J. T.; BARBOSA, E. J. Análise quali-quantitativa da arborização de uma praça do Norte do Brasil. Revista Nativa, Sinop - MT, 2016.

GOMES, G. C., FREITAS, T.C., LUCAS, R.R., MIURA, A. K., SOUSA, L.P., GOMES, E.S., CASCAIS, G. L.B. Espécies Vegetais Recomendadas para Cortinamento em Estações de Tratamento de Esgoto (ETEs) na Região Sul do Rio Grande do Sul. Embrapa Clima Temperado-Documentos (INFOTECA-E), 2017.

GRAMIGNOLLI, V.; GALLO, Z.; SOSSAE, F. C.; QUEDA, O. Arborização viária no Bairro Jardim das Flores, no município de Dourados (SP). Revista Brasileira Multidisciplinar - REBRAM, v. 19, n.1, 2016.

GUIMARÃES, D. F. S.; ALMEIDA, I. C. R.; PATRICIO, A. A.; SILVA, C. F. S.; BUSTAMENTE, N. C. R. Caracterização da Arborização Urbana da Área Central do Município de Manaquiri, Amazonas. Manaquiri - AM, 2014.

HARRI, L; SOUZA, H. M.; TORRES, M. A. V.; BACHER, L. B. Árvores exóticas no Brasil: Madeireiras, ornamentais e aromáticas. Nova Odessa - SP: Instituto Plantarum, 2003. 
IBGE - Instituto Brasileiro de Geografia e Estatística. Censo demográfico 2010. Disponível em: <http://www.censo2010.ibge.gov.br>. Acesso em: 27 de Julho de 2018.

INMET - Instituto Nacional de Meteorologia. Disponível em: <http://www.inmet.gov.br>. Acesso em: 05 de novembro de 2018.

LIMA NETO, E. M.; MELO E SOUZA, R. Comportamento e características das espécies arbóreas nas áreas verdes públicas de Aracaju, Sergipe. Scientia Plena, v. 7, n. 1, 2011.

LORENZI, H. Árvores Brasileiras: manual de identificação e cultivo de plantas arbóreas nativas do Brasil. 2. ed. Nova Odessa: Plantarum, v.2, 1998.

LORENZI, H. Árvores Brasileiras: manual de identificação e cultivo de plantas arbóreas nativas do Brasil. 5. ed. Nova Odessa: Instituto Plantarum, v. 1, 2008.

LOUREIRO, V. R.; BARBOSA, E. J. S. Cidade de Belém e natureza: uma relação problemática?. Periódicos UFPA, Belém, 2010.

MILANO, M.; DALCIN, E. Arborização de vias públicas. $1^{a}$ edição. Rio de Janeiro, 2000.

MINHOTO, E. S.; MONTEIRO, E. A.; FISCH, S. T. V. Arborização viária na cidade de Taubaté-SP: no centro comercial histórico e um bairro residencial moderno. Revista da Sociedade Brasileira de Arborização Urbana, Piracicaba, 2009.

MOURA, I. R. Arborização urbana: Estudo das praças do bairro centro de Teresina. 2010. Dissertação (Mestrado em Geografia) - Universidade Estadual Paulista Júlio de Mesquita Filho, Rio Claro - SP.

NUNES, R. L.; MARMONTEL, C. V. F.; RODRIGUES, J. P.; MELO, A. G. C. Levantamento quali-quantitativo da arborização urbana do bairro Ferraropólis na cidade de Garça - SP. REVSBAU, Piracicaba - SP, 2013.

OLIVEIRA, I. L. Arborização Urbana, Paisagem e Biodiversidade, melhoria da qualidade de vida dos moradores de Cáceres - MT. Universidade do Estado de Mato Grosso - UNEMAT, 2005.

OLIVEIRA, G. N. Manual de recomendações técnicas para projetos de arborização urbana e procedimentos de poda. Secretaria Municipal do Meio Ambiente - SEMAM, Aracruz - ES, 2013.

PAULA, L.; RUBACK, S. S.; TOSTES, R. B.; DUARTE, M. S. Análise das espécies nativas e exóticas da arborização urbana do bairro centro do município de Cataguases, MG. Congresso Nacional de Botânica, Belo Horizonte - MG, 2013.

PAIVA, A. V. Aspectos da arborização urbana do centro de Cosmópolis-SP. Revista da Sociedade Brasileira de Arborização Urbana, Piracicaba - SP, 2009. 
PAIVA, H. N.; GONÇALVES, W. Florestas urbanas: planejamento para melhoria da qualidade de vida. Viçosa: Aprenda Fácil, 2002.

PINTO, L. V. A.; CORRÊA, R. F. M. Conflitos da arborização urbana em vias públicas de Inconfidentes, MG. Congresso Brasileiro de Gestão Ambiental, Bauru - SP, 2010.

PIVETTA, K. F. L.; SILVA FILHO, D. F. Arborização urbana. Jaboticabal: UNESP/FCAV/FUNEP, 2002. 74p. (Boletim Acadêmico. Série Arborização Urbana).

PORTO, L. P. M.; BRASIL, H. M. S.; SILVA, A. C. P.; REIS, A. F. S.; OLIVEIRA, D. B. D.; et al.,; Manual de Orientação Técnica da Arborização Urbana de Belém. Guia para planejamento, implantação e manutenção da arborização em logradouros públicos. Universidade Federal Rural da Amazônia - UFRA, Prefeitura Municipal de Belém (SEMMA), Belém - PA, 2013.

RESENDE, O. M. Arborização Urbana. Universidade Presidente Antônio Carlos UNIPAC, Barbacena, 2011.

RUBIO, A. C. A. S.; AZEVEDO, A. S.; MARCELINO, C. A. P. Manual de Arborização Urbana Bragança Paulista. SEMMA, Bragança Paulista - SP, 2018.

SANCHOTENE, M. C. C. Desenvolvimento e perspectivas da arborização urbana no Brasil. Congresso Brasileiro de Arborização Urbana , 1994, São Luís. Anais... São Luís: Sociedade Brasileira de Arborização Urbana, 1994.

SANTOS, H. C. Arborização urbana no município de Cuité - PB: Levantamento florístico e percepção ambiental dos moradores. Monografia (Pós - Graduação em Gestão dos Recursos Ambientais do Semiárido) - Instituto Federal de Educação, Ciência e Tecnologia da Paraíba, Picuí - PB, 2018.

SANTOS, A. R.; BERGALLO, H. G.; ROCHA, C. F. D. Paisagem urbana alienígena. Rio de Janeiro: Ciência Hoje, 2008.

SCARAMUSSA, L. M. Levantamento quali-quantitativo da arborização urbana e percepção dos moradores da cidade de Vargem Alta - ES. Monografia Universidade Federal do Espirito Santo, Jerônimo Monteiro - ES, 2013.

SMAAP - Secretaria de Meio Ambiente, Agricultura e Pesca. Cartilha Arborização Urbana. Estância Balneária de Caraguatatuba. Caraguatatuba - SP, 2016.

SEMAS - Secretaria de Meio Ambiente e Sustentabilidade. Plano diretor de arborização urbana. Prefeitura de Manaus - AM, 2017.

Secretaria Municipal do Verde e do Meio Ambiente da Prefeitura de São Paulo. Manual Técnico de Arborização Urbana. São Paulo - SP, 2015. 
SCHUCH, M. I. S. Arborização urbana: Uma contribuição à qualidade de vida com o uso de geotecnologias. 2006. Dissertação (Mestrado em Geomática) Universidade Federal de Santa Maria, Santa Maria - RS.

SCHALLENBERGER, L. S.; MACHADO, G. de O. Inventário da arborização na região central do município de Mangueirinha - PR. Revista da Sociedade Brasileira de Arborização Urbana, Piracicaba - SP, 2013.

SILVA, A. G.; CARDOSO, A. L.; RAPHAEL, M. Diagnóstico quali-quantitativo da arborização viária da cidade de Jeronimo Monteiro - ES. Enciclopédia Biosfera, Goiânia, GO, v.8, n.14, 2012.

SILVA FILHO, D. F.; PIZETTA, P. U. C.; ALMEIDA, J. B. S.; PIVETTA, K. F. L; FERRAUDO, A. S. Banco de dados relacional para cadastro, avaliação e manejo da arborização em vias públicas. Revista Árvore, Viçosa, 2002.

UFRJ - Museu Nacional - Horto Botânico. Disponível em: < http://museunacional.ufrj.br/hortobotanico/arvoresearbustos/ficusbenjamina.htm > Acesso em: 19/09/ 2018.

VELASCO, G. D. N. Arborização viária x sistema de distribuição de energia elétrica: Avaliação dos custos, estudo das podas e levantamento de problemas fitotécnicos. Piracicaba: Universidade Superior de Agricultura "Luiz de Queiroz", Dissertação (Mestrado em Fitotecnia), 2003.

ZILLER, S. R. A Estepe Gramíneo-Lenhosa no segundo planalto do Paraná: diagnóstico ambiental com enfoque à contaminação biológica. UFP - Curitiba, 2000.

ZILLER, S. R.; ZENNI, R. D.; DECHOUM, M. S. Espécies exótica invasoras na arborização urbana: Problemas e soluções. Congresso Brasileiro de Arborização Urbana, Vitória - ES, 2007. 